\title{
An Investigation on the Optimum Corrosion Protection Potential for Minimization of Cavitation Damage Using the Potentiostatic Method in Seawater
}

\author{
Seong-Jong Kim, ${ }^{1, \star}$ Seok-Ki Jang, ${ }^{1}$ and Jae-Cheul Park ${ }^{2}$ \\ ${ }^{1}$ Division of Marine System Engineering, Mokpo Maritime University, Haeyangdaehak-ro 91 Mokpo-si, \\ Jeonnam 530-729, Korea \\ ${ }^{2}$ Korean Register of Shipping, 17, Gukhoe-daero 68-gil, Yeongdeungpo-gu, Seoul 150-871, Republic of Korea
}

\begin{abstract}
In this study, we replaced the expensive blade material with an aluminum-bronze alloy that has excellent corrosion resistance and cavitation characteristics and developed the corrosion protection method to improve durability using an electrochemical method. The objective of this study was to identify the electrochemical corrosion protection conditions to minimize cavitation damage due to generating hydrogen gas $\left(2 \mathrm{H}_{2} \mathrm{O}+\right.$ $2 \mathrm{e}^{-} \rightarrow 2 \mathrm{OH}^{-}+\mathrm{H}_{2}$ ) by means of hydrogen overvoltage before the impact pressure of the cavity is transferred to the surface. In the constant potential experiment under the cavitation environment, the energy was reflected or cancelled out by collision of the cavities with the hydrogen gas generated by the hydrogen overvoltage. As a result, the optimal corrosion prevention potential in the dynamic state is assumed to be the range of -1.4 to $-1.7 \mathrm{~V}$, which is the range at which active polarization took place.
\end{abstract}

Key words: aluminum-bronze alloy, electrochemical corrosion protection condition, hydrogen overvoltage, cavitation environment

\section{INTRODUCTION}

Power generated from tidal current has the advantage of being a reliable energy source. The generation of such power entails low cost as a large-scale dam need not be constructed; in addition, the power generation is predictable regardless of the changing weather or season (Lee et al., 2004; Liu et al., 2011). However, for the generation of a large amount of energy, the change in sea level due to the ebb and flow of the tide should be large and the flow rate should be high. Thus, a sufficiently strong material is required to generate energy from the load caused by such a tidal current. The materials used in tidal current power generation facilities are polymer composite materials such as carbon fiber or glass fiber that have high strength and high elasticity as well as high resistance to the chemically corrosive environment. These materials have the advantage of being able to produce high energy because of their low specific gravity, but the resistance to impact is low, the price is high, and fabrication is difficult. Besides composite materials, high-toughness and high-strength stainless steel is also used, but its strength is drastically reduced when a pitting corrosion takes place due to chloride ions in seawater, which is a harsh corrosive environment (Kim et al., 2011). To solve these problems, we replaced the expensive blade material with an aluminum-bronze alloy that has excellent corrosion resistance and cavitation characteristics, and developed the corrosion protection method to improve durability by means of an electrochemical method.

(c) MICROSCOPY SOCIETY OF AMERICA 2013

${ }^{\star}$ Corresponding author. E-mail: ksj@mmu.ac.kr

\section{Materials and Methods}

All of the potentiostatic experiments and hybrid potentiostatic tests under cavitation conditions were conducted in aerated natural seawater and carried out under various potential parameters. On the basis of the ASTM-G32 regulation, the hybrid potentiostatic test was performed using the cavitation generator, RB 111-CE (cavitation erosion tester, R\&B, Korea), which uses the piezoelectric effect. Electric powers of $60 \mathrm{~Hz}$ and $220 \mathrm{~V}$ were supplied through the electronic circuit to the vibrator after generating $20 \mathrm{kHz}$ of vibration nominal power. The constant amplitude automatic control system maintained the amplitude at $10 \mu \mathrm{m}$. The ALBC3 specimens used for the electrochemical experiments and hybrid potentiostatic tests in this investigation were mounted with epoxy resin and polished with \#2000 emery paper. The objective of this study was to identify the electrochemical corrosion protection conditions to minimize the cavitation damage due to generating hydrogen gas $\left(2 \mathrm{H}_{2} \mathrm{O}+2 \mathrm{e}^{-} \rightarrow 2 \mathrm{OH}^{-}+\mathrm{H}_{2}\right)$ by means of hydrogen overvoltage before the impact pressure of the cavity is transferred to the surface. First, the constant potential conditions were set after analyzing the cathodic polarization trend of the aluminum-bronze alloy in the seawater environment. The chosen condition corresponded to the potential in the active polarization range $(-1.1$ to $-2.0 \mathrm{~V})$, which was below the range of the concentration polarization by the dissolved oxygen reduction reaction in the cathodic polarization curve of the aluminum-bronze alloy. By maintaining each of the conditions for 90,000 s, the surface damage behavior was analyzed depending on the existence of the cavitation environment. Moreover, following the po- 


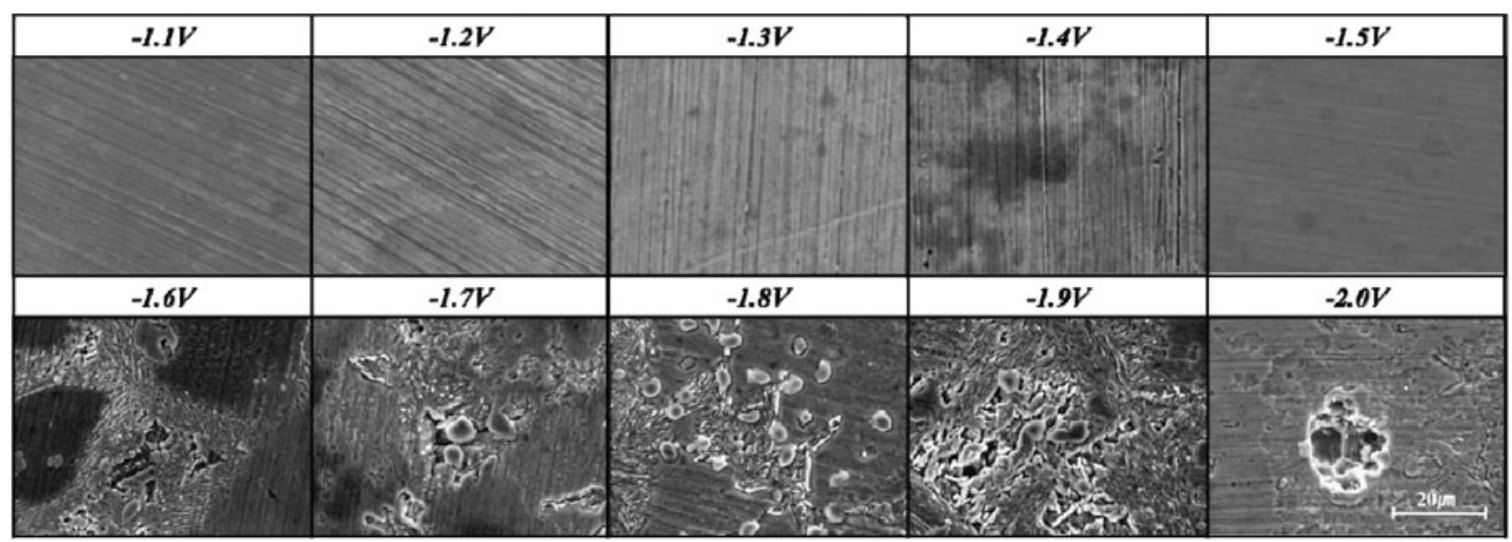

(a)

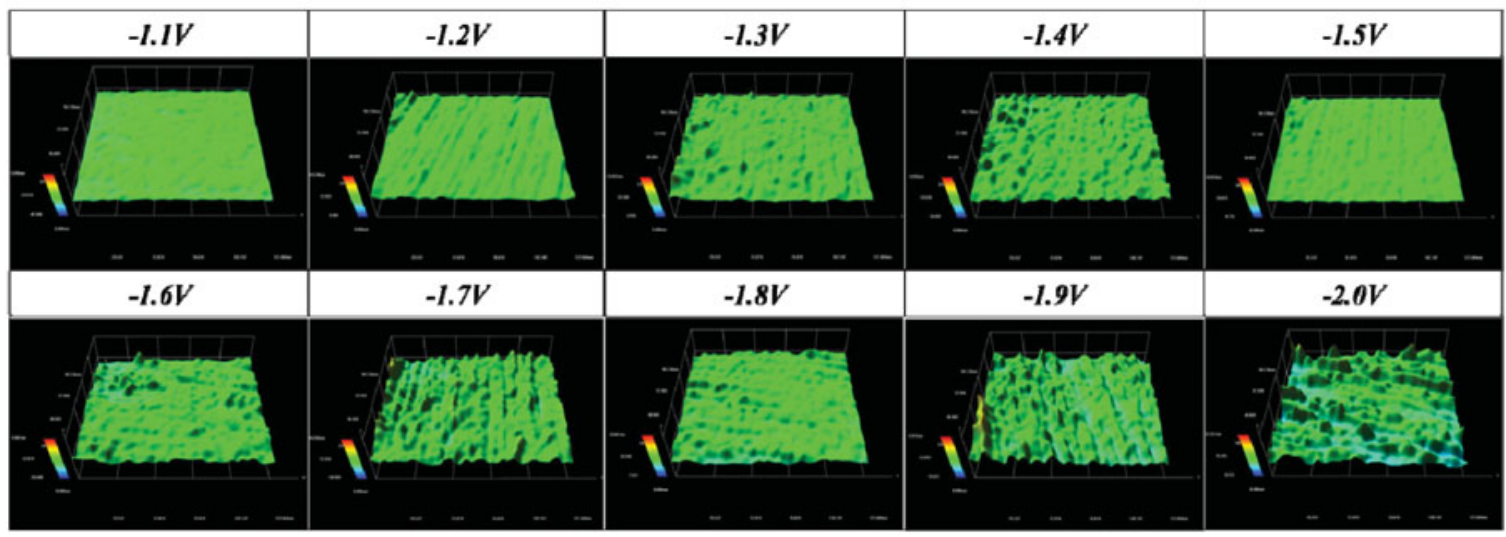

(b)

Figure 1. Surface morphologies and three-dimensional (3D) analysis of the ALBC3 base metal after a potentiostatic experiment over 25 h. a: Surface morphologies using a scanning electron microscope. b: 3D analysis using a 3D analytical microscope.

tentiostatic and hybrid potentiostatic tests, we observed the specimen surfaces of different conditions using a threedimensional analytical microscope and a scanning electron microscope (SEM) to measure the depth of the electrochemical and cavitation damage and analyzed the individual characteristics and the complex behavior at the affected surface by cavitation.

\section{Results AND Discussion}

Figure 1 presents the surface state under each of the potential conditions observed with the SEM and the three-dimensional (3D) analysis microscope after performing the dynamic potential experiment for 90,000 $\mathrm{s}$ with the aluminum-bronze alloy in the seawater environment. First, the SEM image in Figure 1a shows the surface under $2,000 \times$ magnification; the degree of damage can be seen to be distinctively different between the region that was damaged by the active polarization and the region that was not damaged. The surface damage was drastically increased in the applied potential region below $-1.6 \mathrm{~V}$, but there was almost no surface damage in the applied potential region between -1.1 and $-1.5 \mathrm{~V}$, except for the scratch formed mostly during polishing. Damage was found in the applied potential region below $-1.6 \mathrm{~V}$, and it increased as the potential was increased. Particularly, the surface damage at the potential of $-2.0 \mathrm{~V}$ was in the form of a relatively serious local crater in the depth direction. In contrast, the $3 \mathrm{D}$ analysis image in Figure $1 \mathrm{~b}$ shows the surface under $200 \times$ magnification, and the overall surface damage was observed as the magnification was smaller than that of the SEM image. The 3D analysis showed that the surface roughness was increased as the applied potential was decreased. Especially in the potential region between -1.1 and $-1.5 \mathrm{~V}$, the surface was very smooth and almost no corrosive damage was found. However, from the potential of $-1.6 \mathrm{~V}$, the overall surface roughness was constantly increased, which was consistent with the surface damage trend seen in the SEM image (Fig. 1a).

Figure 2 shows the surface state under each of the potential conditions observed with the SEM and the 3D analysis microscope after performing the cavitationpotentiostatic hybrid test for 90,000 s with the aluminumbronze alloy in the seawater environment. The SEM image in Figure 2a shows a surface damage that took place in a local region and the surface damage by the cavitation 


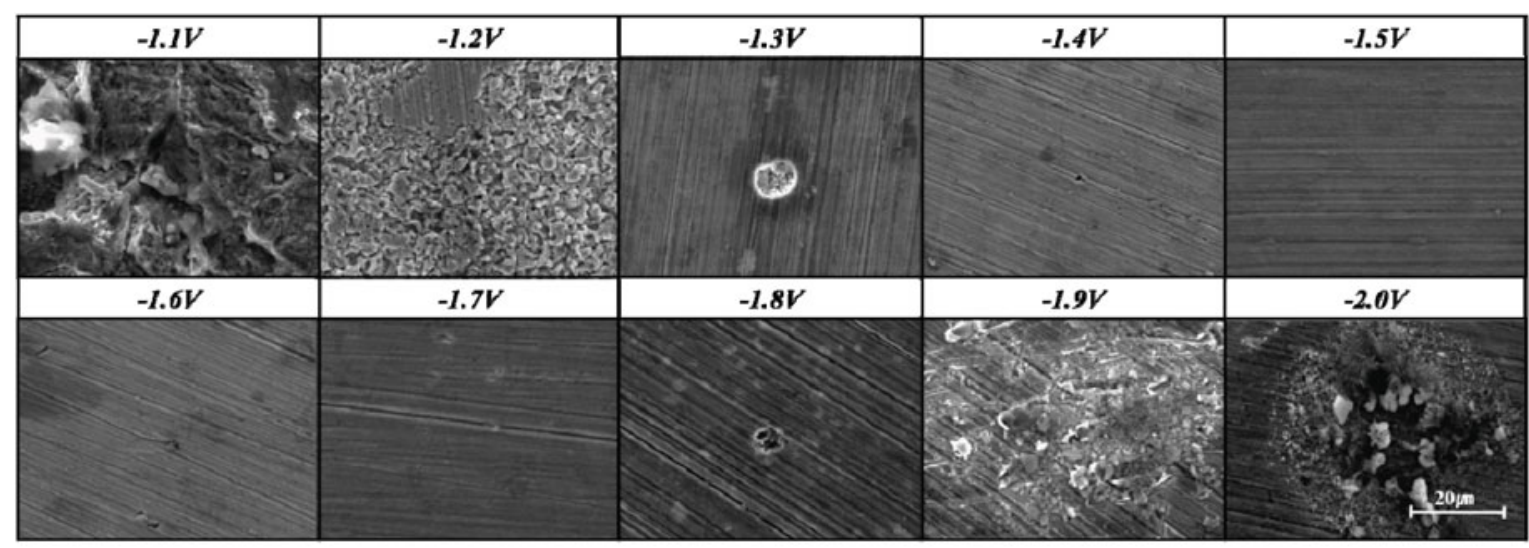

(a)

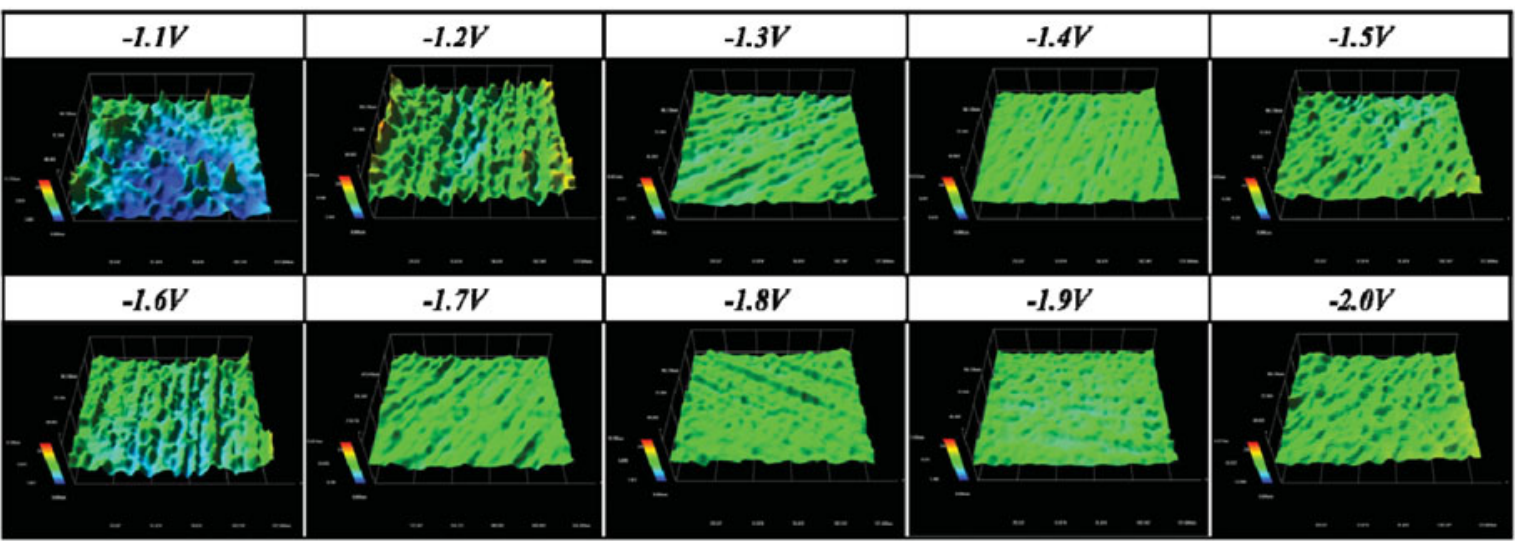

(b)

Figure 2. Surface morphologies and 3D analysis of the ALBC3 base metal after hybrid potentiostatic test over $25 \mathrm{~h}$. a: Surface morphologies using a scanning electron microscope. b: 3D analysis using a 3D analytical microscope.

impact pressure at the potentials of -1.1 and $-1.2 \mathrm{~V}$ was relatively severe. In contrast, there was almost no surface damage in the potential region between -1.4 and $-1.7 \mathrm{~V}$, and the cavitation damage in the form of local craters was found on the surface at the potentials of -1.3 and $-1.8 \mathrm{~V}$. However, in most of the regions, a clean surface without damage was found. The reason why the surface damage was little despite the imposed cavitation environment may be because the hydrogen gas generated by the active polarization cancelled out the energy of the cavities by colliding with them so that the cavitation impact pressure could not be transferred to the material surface. However, if the active polarization becomes more active on the material surface by the decrease in potential, damage can occur as the hydrogen gas generation is increased by the reduction of hydrogen ions in the seawater solution. Further, hydrogen atoms damage the surface by penetrating into the material and causing hydrogen-induced cracking during the active polarization process (Michler et al., 2009; Elhoud et al., 2010). In this study, the surface damage began to be seen from the potential below $-1.9 \mathrm{~V}$. As shown in Figure 2, the damage pattern in the region below $-1.9 \mathrm{~V}$ was different from that in the potential region of -1.1 to $-1.3 \mathrm{~V}$, and the degree of surface damage was comparatively small. However, the hydrogen-induced cracking by the hydrogen atoms that have penetrated into the material requires a latent period and is accelerated when a tensile strength is applied. Thus, the cavitation-corrosion prevention limit potential over which the hydrogen-induced cracking can take place needs to be identified. The $3 \mathrm{D}$ analysis in Figure $2 \mathrm{~b}$ shows that the surface was the roughest at the applied potentials of -1.1 and $-1.2 \mathrm{~V}$ but there was no cavitation damage in general on the surface of the specimen under the potential below $-1.3 \mathrm{~V}$. Moreover, it seemed that the damage was surface reduced at the potential of -1.9 and $-2.0 \mathrm{~V}$, by the active polarization process.

Figure 3 shows the comparison of the mean depth of damage measured using the 3D microscope after the constant potential experiment and that measured using the cavitation-potentiostatic hybrid test with the aluminumbronze alloy in the seawater environment. The mean depth of damage was generally smaller in the cavitationpotentiostatic hybrid test under the cavitation environment than in the constant potential experiment under the static condition at all the applied potentials, and the values were constant in general. However, in the case of the constant potential experiment under the static condition, the mean depth of damage was increased to some extent as the 


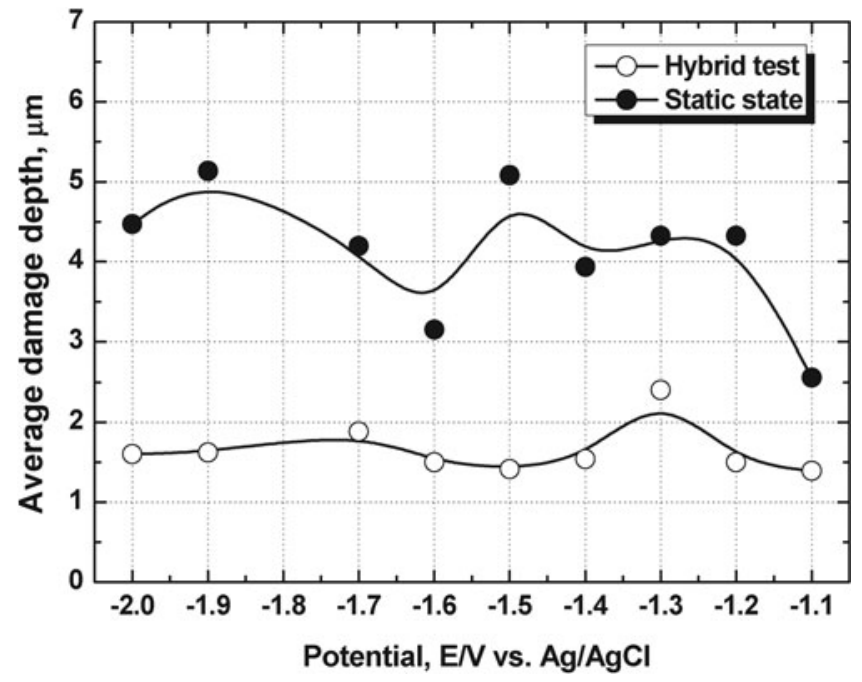

Figure 3. Comparison of the average damage depth with applied potential.

potential was decreased. This was consistent with the trend in Figure 1 in that the surface damage was increased as the potential was decreased. The surface damage by the hydrogen gas generation was distinctive in the static state, as previously mentioned in Figures 1 and 2, but the damage by the active polarization and the cavitation was less in the dynamic state than in the static state. Hence, it is assumed that the cavitation damage can be prevented by generating hydrogen gas with inducing active polarization electrochemically. The optimal cathodic corrosion prevention conditions in the static and dynamic states depending on the existence of the cavitation environment are based on the electrochemical polarization reaction that is completely in contrast to the concentration polarization region and the active polarization region of the dissolved reduction reaction. Therefore, the optimal corrosion prevention potential in the dynamic state is assumed to be in the range of -1.4 to $-1.7 \mathrm{~V}$, at which range the active polarization took place.

\section{CONCLUSION}

1. In the constant potential experiment under the cavitation environment, energy was reflected or cancelled out by the collision of the cavities with the hydrogen gas generated by the hydrogen overvoltage, and almost no cavitation damage was found especially in the potential region below $-1.4 \mathrm{~V}$. In contrast, the surface damage occurred locally due to the active polarization in the potential region lower than $-1.9 \mathrm{~V}$.

2. The surface observation showed that neither the cavitation damage nor the electrochemical damage by the hydrogen gas generation occurred in the potential region of -1.4 to $-1.7 \mathrm{~V}$ in the dynamic state under the cavitation environment. This may be because the number of hydrogen atoms penetrating through the material surface was decreased by the continuous consumption of hydrogen atoms as the cavities collided with the hydrogen gas.

\section{ACKNOWLEDGMENTS}

This research was financially supported by the Ministry of Education, Science Technology (MEST) and Korea Industrial Technology Foundation (KOTEF) through the Human Resource Training Project for Regional Innovation.

\section{RefERENCES}

Elhoud, A.M., Renton, N.C. \& Deans, W.F. (2010). Hydrogen embrittlement of super duplex stainless steel in acid solution. Int J Hydrogen Energy 35, 6455-6464.

Kim, S.T., Kim, S.Y., Lee, I.S., PARK, Y.S., Shin, M.C. \& Kim, Y.S. (2011). Effects of shielding gases on the microstructure and localized corrosion of tube-to-tube sheet welds of super austenitic stainless steel for seawater cooled condenser. Corrosion Sci 53, 2611-2618.

Lee, H.J., Jo, H.R., Chu, Y.S. \& Bahк, K.S. (2004). Sediment transport on macrotidal flats in Garolim Bay, west coast of Korea: Significance of wind waves and asymmetry of tidal currents. Continental Shelf Res 24, 821-832.

Liu, H.W., MA, S., LI, W., Gu, H.G., Lin, Y.G. \& Sun, X.J. (2011). A review on the development of tidal current energy in China. Renewable Sustainable Energy Rev 15, 1141-1146.

Michler, T., Lee, Y.W., Gangloff, R.P. \& Naumann, J. (2009). Influence of macro segregation on hydrogen environment embrittlement of SUS 316L stainless steel. Int J Hydrogen Energy 34, 3201-3209. 